Int. J. Dev. Biol. 56: 833-839 (2012)

doi: $10.1387 / \mathrm{ijdb} .120136 \mathrm{pw}$

\title{
Influence of the zona pellucida of the mouse egg on folliculogenesis and fertility
}

\author{
PAUL M. WASSARMAN* and EVELINE S. LITSCHER \\ Department of Developmental and Regenerative Biology, Mount Sinai School of Medicine, New York, NY, USA
}

\begin{abstract}
All mammalian eggs are surrounded by a relatively thick extracellular coat, called the zona pellucida (ZP), that plays vital roles during oogenesis, fertilization, and preimplantation development. The mouse egg ZP consists of three glycoproteins, called mZP1-3, that are synthesized solely by oocytes during their 2-to-3 week growth phase. The ZP is seen initially as isolated extracellular deposits of nascent ZP fibrils that coalesce to form a thickening matrix. Elimination of ZP glycoprotein synthesis by targeted mutagenesis yields mice that are heterozygous or homozygous for the null mutations. Homozygous null males are unaffected by the mutations and heterozygous females are as fertile as wild-type females. On the other hand, eggs from $m Z P 2-/$-and $m Z P 3-/-$ females lack a ZP and the mice are completely infertile due to a severely reduced number of ovulated eggs in their oviducts. Development of ovarian follicles is retarded in homozygous null females and manifested as reduced ovarian weight, number of Graafian follicles, and number of ovulated eggs. Eggs from $m Z P 1-/-$ females have a distorted ZP and, although the mice are fertile, they exhibit reduced fertility due to early embryonic loss. Potential relationships between ZP biogenesis, folliculogenesis, and fertility are addressed.
\end{abstract}

KEY WORDS: ovary, oocyte, follicle, zona pellucida, mZP1, mZP2, mZP3, null mutant, fertility

\section{Introduction}

The zona pellucida (ZP) is a relatively thick, viscous, and elastic extracellular coat that surrounds all mammalian oocytes, ovulated eggs, and pre-implantation embryos (Wassarman, 1988) (Fig. 1). It is a highly specialized extracellular coat that carries out functions unique to mammalian reproduction. The ZP ranges in thickness from less than $1 \mu \mathrm{m}$ to more than $25 \mu \mathrm{m}$ ( $1-30 \mathrm{ng}$ protein) for eggs from different mammals and consists of a network of interconnected fibrils. The innermost fibrils are oriented radially to the oocyte's plasma membrane and are closely packed, whereas the outermost fibrils are oriented tangentially and are more loosely packed (Keefe et al., 1997). The ZP is known to be quite porous and permeable to relatively large macromolecules, including many small viruses. Expanded blastocysts ( day-4.5) hatch from the ZP using (a) specific protease(s) just prior to implantating into the uterus.

The ZP is a vital participant in mammalian reproduction, playing important roles during oogenesis, fertilization, and preimplantation development. For example, during fertilization sperm must bind to and penetrate the ZP in order to reach and fuse with the egg's plasma membrane. In this context, the ZP prevents fusion of sperm from most, but not all heterologous species, with plasma membrane of ovulated eggs (i.e., the ZP supports species-restricted fertilization). It also prevents supernumerary sperm from binding to and penetrating eggs following fusion of an egg with a single sperm (i.e., the ZP assists in preventing polyspermic fertilization) (Wassarman, 1999; Hardy, 2002; Florman and Ducibella, 2006). Following ovulation and fertilization, the ZP protects cleavagestage embryos over several days as they traverse the oviduct on their way to the uterus.

Because of the ZP's vital role in mammalian reproduction, it has been investigated intensively during the past few decades. With the advent of gene targeting procedures it has been possible to establish mouse lines in which genes encoding ZP glycoproteins have been inactivated by homologous recombination and insertional mutagenesis. This experimental approach has made it possible to examine relationships between ZP formation, follicle development, and fertility. Results of these investigations emphasize the importance of ZP formation for normal folliculogenesis and fertility in mice, in particular, and in mammals, in general.

Abbreviations used in this paper: $\mathrm{mZP}$, mouse zona pellucida; ZP, zona pellucida; ZPD, zona pellucida domain.

\footnotetext{
*Address correspondence to: Paul M. Wassarman or Eveline S. Litscher. Dept. of Developmental and Regenerative Biology, Mount Sinai School of Medicine, One Gustave L. Levy Place, New York, NY 10029-6574, USA. e-mails: paul.wassarman@mssm.edu; eveline.litscher@mssm.edu
} 


\section{Appearance of the mouse egg zona pellucida during oogenesis}

Unfertilized eggs are the end-product of oogenesis, a process that is initiated during fetal development and ends months-to-years later in the sexually mature adult (Austin and Short, 1982; Wassarman and Albertini, 1994). Oogenesis in mice begins with the appearance of primordial germ cells (fetal days 7-9) which become the oogonia that populate fetal ovaries (fetal days 11-12). Oogonia in turn become non-growing oocytes (fetal days 12-14) that populate ovaries of neonatal mice. Non-growing oocytes do not have a ZP. The transition from oogonia to oocytes involves a change from mitotic to meiotic cells. Progression through the first meiotic prophase (leptotene, zygotene, pachytene, and diplotene), with pairing of homologous chromosomes, crossing-over, and recombination, takes 4-5 days. Shortly after birth (post-coitus day-21), nearly all oocytes are arrested in late diplotene (so-called, dictyate-stage), where they remain until stimulated to resume meiotic progression at the time of ovulation. This pool of small, non-growing oocytes is the source of unfertilized eggs in the sexually mature mouse $(\sim 6$ weeks-of-age).

In sexually mature mice, each ovary contains $\sim 8,000$ non-growing oocytes. Each non-growing oocyte $(\sim 12 \mu \mathrm{m}$ in diameter; $\sim 0.9 \mathrm{pl}$ in volume) is contained within a follicle ( $17 \mu \mathrm{m}$ in diameter) that grows concomitantly with the oocyte. The follicle grows from a single layer of a few epithelial-like cells to three layers of cuboidal cells ( $\sim 900$ cells; $\sim 125 \mu \mathrm{m}$ in diameter) by the time the oocyte has completed its growth ( $\sim 80 \mu \mathrm{m}$ in diameter; $\sim 270 \mathrm{pl}$ in volume). It is during the $\sim 2$-week growth phase, while oocytes are continually arrested at the dictyate-stage of the first meiotic prophase, that they acquire a ZP. The ZP is initially seen as isolated extracellular pockets of nascent ZP fibrils (Fig. 2) that coalesce in time to form a thickening ZP (Wassarman and Mortillo, 1991). As a growing oocyte increases in diameter its ZP increases in thickness, achieving a

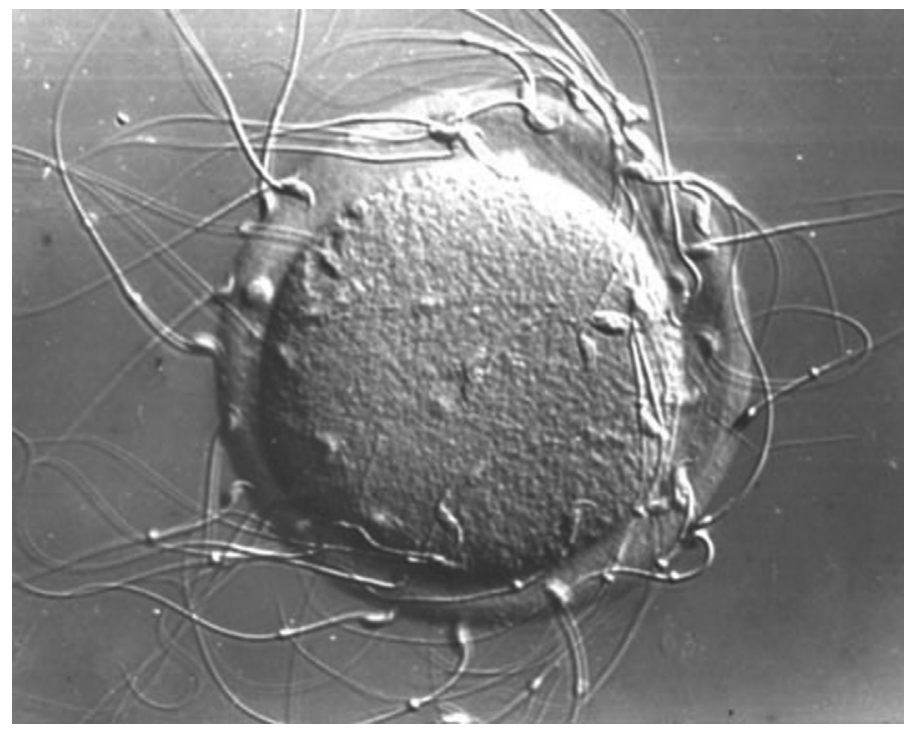

TABLE 1

\section{OOCYTE DIAMETER AND ZONA PELLUCIDA WIDTH}

\begin{tabular}{cc} 
Oocyte Diameter $(\mu \mathrm{m})$ & ZP Width $(\mu \mathrm{m})$ \\
\hline 40 & $1.6 \pm 0.4$ \\
50 & $2.5 \pm 0.7$ \\
60 & $3.5 \pm 0.9$ \\
70 & $5.6 \pm 1.3$ \\
80 & $6.2 \pm 1.9$ \\
\hline
\end{tabular}

Relationship between oocyte diameter $(\mu \mathrm{m})$ during oocyte growth and the width of the ZP $(\mu \mathrm{m})$

final width of $6.2 \pm 1.9 \mu \mathrm{m}$ (Table 1).

Once the oocyte is fully-grown, the follicle undergoes enormous growth, increasing to $\sim 60,000$ cells, and results ultimately in a Graafian follicle, greater than $600 \mu \mathrm{m}$ in diameter. The follicle exhibits a fluid-filled cavity, or antrum, when it is several layers thick ( 6,000 cells; $\sim 250 \mu \mathrm{m}$ in diameter). As the antrum expands, the oocyte takes up an acentric position surrounded by two or more layers of cells, called cumulus cells. The innermost layer of cumulus cells surrounding the oocyte becomes columnar in shape and constitutes the corona radiata. Cells of the corona radiata form specialized intercellular junctions, called gap junctions, with the plasma membrane of the oocyte. A fully-developed Graafian fol-

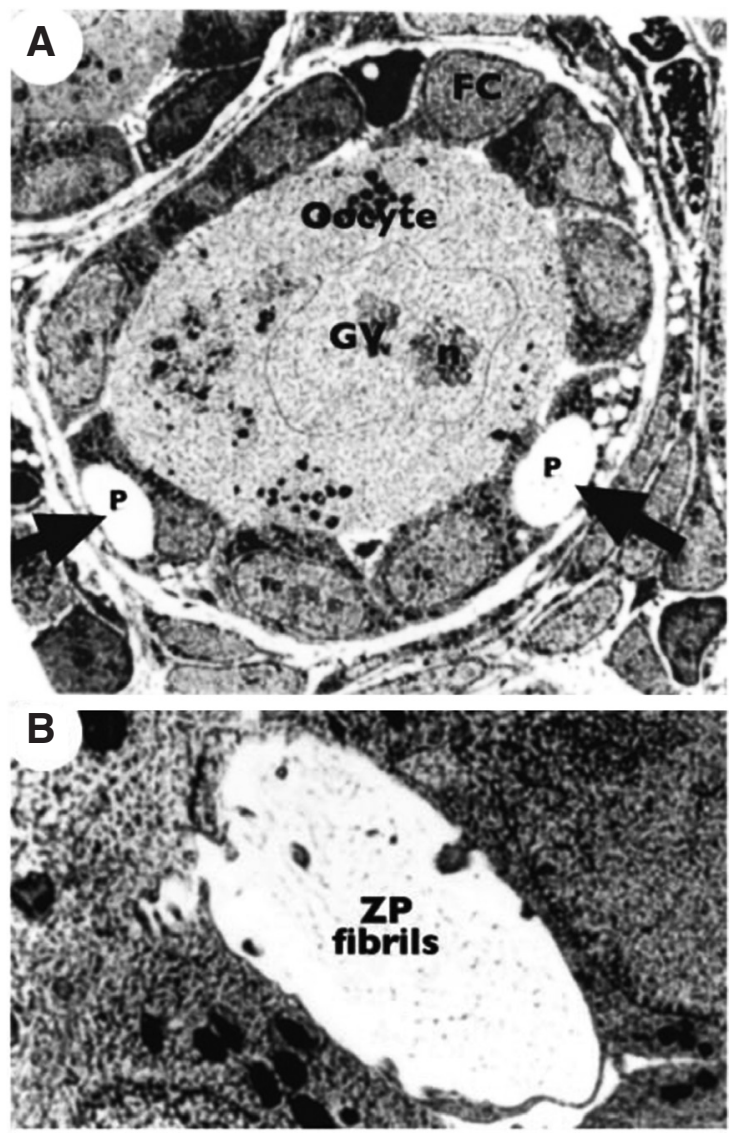

Fig. 1 (Left). Binding of free-swimming sperm to the zona pellucida (ZP) of an ovulated mouse egg. The light micrograph was taken using Nomarski differential interference contrast microscopy.

Fig. 2 (Right). Transmission electron micrograph of a developing mouse follicle. (A) Note the pockets ( $p$; arrowheads) of nascent ZP fibrils that form between the growing oocyte and surrounding follicle cells. gv, germinal vesicle (nucleus) of the oocyte. (B) Higher magnification view of a pocket of nascent ZP fibrils present in the micrograph shown in (A). 
licle consists of one fully-grown oocyte positioned at the end of a stalk of follicle cells and surrounded by several layers of cumulus cells and a large, fluid-filled antrum. At ovulation, in response to hormones, the oocyte surrounded by cumulus cells is expelled from the Graafian follicle, resumes meiosis, moves into the oviduct, and becomes an unfertilized egg arrested at metaphase II. Simultaneously, the group of follicle cells left behind becomes an endocrine gland, called the corpus luteum. The latter supports pregnancy by secretion of progesterone after implantation of expanded blastocysts into the uterus.

\section{Characterization of mouse zona pellucida glycoproteins}

Each mouse egg ZP contains $\sim 3.5 \mathrm{ng}$ of protein $(-10 \%$ of total egg protein) and only three glycoproteins, called mZP1 ( 200 kDa; 1,246 amino acids; dimer), mZP2 ( 120 kDa; 713 amino acids; monomer), and mZP3 ( $~ 83$ kDa; 424 amino acids; monomer) account for the protein content (Bleil and Wassarman, 1980; Shimizu et al., 1983; Wassarman, 1988, 2008). mZP2 and mZP3 are present in the ZP in approximately equimolar amounts and represent $\sim 80 \%$ of total ZP protein; mZP1 represents only $\sim 20 \%$ of total ZP protein. ZP polypeptides are heterogeneously glycosylated with complex-type, asparagine-linked ( $\mathrm{N}-$ ) and serine/threonine-linked (O-) oligosaccharides that causes them to migrate as broad bands on SDS-PAGE. mZP1-3 possess 4, 6, and $5 \mathrm{~N}$-linked oligosaccharides/polypeptide (Boja et al., 2003). The oligosaccharides are both sialylated and sulfated such that native mZP1-3 have rather low isoelectric points (Wassarman, 1988; Liu et al., 1997). The heterogeneity and acidic nature of ZP glycoproteins is due entirely to their $\mathrm{N}$ - and $\mathrm{O}$-linked oligosaccharides and not to their polypeptides.

ZP polypeptides from different mammals are well conserved. ZP2 and ZP3 exhibit $\sim 65-98 \%$ identity and ZP1 $\sim 40 \%$ identity. For example, the sequences of mouse and human ZP2 and ZP3, two species separated by more than 100 million years of evolution, are $56 \%$ and $67 \%$ identical, respectively. ZP polypeptides

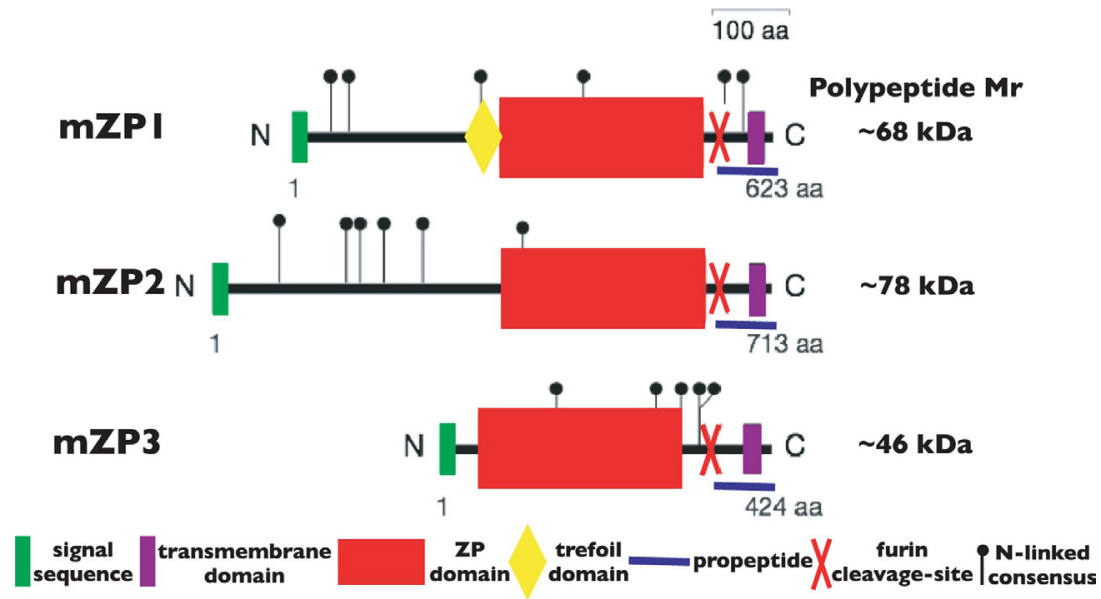

Fig. 3. Schematic representation of the overall architecture of mouse zona pellucida (ZP) glycoproteins mZP1, mZP2, and mZP3. The polypeptide of each ZP glycoprotein is drawn to scale with the $N$ - and C-termini indicated. Shown are the signal peptide (green), trefoil domain (yellow), ZP domain (red), consensus furin cleavage-site (red X), transmembrane domain (purple), and C-terminal propeptide region (blue bar). Putative $N$ linked glycosylation sites are shown (black lollipops). The number of amino acids in each polypeptide is indicated. have several regions in common, suggesting that they may be derived from a common ancestral gene. Nascent mZP1-3 are synthesized as precursor polypeptides that have an $\mathrm{N}$-terminal signal-sequence that directs nascent glycoproteins to the secretory pathway, a C-terminal propeptide that has a consensus furin cleavage-site, a transmembrane domain downstream of the consensus furin cleavage-site, and a short cytoplasmic tail. In addition, mZP1 has a trefoil domain (Wassarman, 2008) (Fig. 3).

mZP1-3 also have an $\sim 260$ amino acid sequence, called a ZP domain (ZPD) (Bork and Sander, 1992), that contains 8 conserved Cys residues present as intra-molecular disulfides (Fig. 3). ZPDs are found in hundreds of proteins of diverse functions from a wide variety of tissues in all multi-cellular eukaryotes. ZPD proteins are often glycosylated modular structures consisting of multiple types of domains (Jovine et al., 2005). Several of these proteins are known to assemble into fibrils and play a role in organizing and shaping specialized apical structures in epithelial cells (Plaza et al., 2010). Mutations in genes encoding ZPD proteins can result in severe human pathologies, including infertility, deafness, and cancer. ZPDs are bipartite structures consisting of an N-terminal sub-domain with 4 conserved Cys residues and a C-terminal subdomain separated by a short, protease-sensitive, linker region (Jovine et al., 2004; Llorca et al., 2007; Han et al., 2010). Several proteins have been identified in flies, mice, and man that consist of only the N-terminal sub-domain. None have been found that consist of only the C-terminal sub-domain (Jovine et al., 2006).

\section{Assembly of zona pellucida glycoproteins into an extracellular matrix}

Several lines of evidence strongly suggest that mZP2 and mZP3 are synthesized exclusively and secreted independently by growing oocytes (Wassarman, 2008). However, mZP2 and mZP3 are dependent on each other for incorporation into the ZP and apparently do so by a stochastic process (Tong et al., 1995; Qi and Wassarman, 1999; Hoodbhoy et al., 2006). In this context, isolated ZPDs polymerize into long fibrils on their own and it is the $\mathrm{N}$-terminal sub-domain that is responsible for polymerization (Jovine et al., 2002). This is of particular interest since ultrastructural analyses of solubilized ZP reveal their fibrillar nature, with long fibrils interconnected by ZP1 (a dimer held together by intermolecular disulfides) and exhibiting a structural repeat $(\sim 140 \AA)$ attributed to mZP2-mZP3 dimers (Greve and Wassarman, 1985; Wassarman and Mortillo, 1991; Wassarman et al., 1996).

The three-dimensional structure of chicken ZP3 (cZP3; 53\% identical to human ZP3) has been determined at $\sim 2.0 \AA$ Å resolution using X-ray crystallographic methods (Monné et al., 2008; Han et al., 2010; Monné and Jovine, 2011). The ZPD N- and C-terminal sub-domains adopt immunoglobulin (lg)-like folds, suggesting that ZP polypeptides may have arisen by duplication of a common Iglike domain. Furthermore, within crystals, cZP3 forms anti-parallel dimers stabilized by interactions between the $\mathrm{N}$ - and $\mathrm{C}$-terminal sub-domains of opposing cZP3 molecules. It is likely that mZP2-mZP3 
dimers adopt a similar orientation within ZP fibrils and give rise to the aforementioned $\sim 140 \AA$ structural repeat.

\section{Production of $m Z P 1-3$ null females}

mZP1-3 polypeptides are encoded by single-copy genes located on three different chromosomes; $m Z P 1-3$ are on chromosomes 19, 7, and 5, respectively (Lunsford et al., 1990; Epifano et al., 1995). Genes encoding mZP1-3 consist of 12, 18, and 8 exons, respectively, and the number and length of exons is highly conserved among mammalian species. Homozygous and heterozygous $m Z P 1-3$ null mice were produced using homologous recombination and insertional mutagenesis in embryonic stem cells by standard gene targeting procedures (Ramirez-Solis et al., 1993). It should be noted that disruption of $m Z P 1-3$ genes had no effect at all on male mice.

\section{Disruption of the mZP1 gene on chromosome 19}

The targeting construct was made using $m Z P 1$ isolated from mouse genomic DNA. The construct contained $12 \mathrm{~kb}$ of isogenic DNA, $3.0 \mathrm{~kb} 5$ ' to the transcription start-site and $9.2 \mathrm{~kb}$ extending from exon-3 into the 3'-flanking region (Rankin et al., 1999).

\section{Disruption of the mZP2 gene on chromosome 7}

The targeting vector was constructed using a genomic clone of $m Z P 2$ obtained by screening mouse genomic DNA with $m Z P 2$ cDNA. The construct contained $6.2 \mathrm{~kb}$ of isogenic DNA, $1.2 \mathrm{~kb} 5$ ' to the transcription start-site and $5.0 \mathrm{~kb}$ extending from intron- 2 to intron-7 (Rankin et al., 2001).

\section{Disruption of the MZP3 gene on chromosome 5}

Two different contructs were used to target $m Z P 3$. (i) A targeting vector was constructed such that part of $m Z P 3$ exon- 2 and -3 , and all of intron-2, were replaced by the positive selection marker pGKneo cassette (Liu et al., 1996). (ii) Another targeting vector was constructed such that $m Z P 3$ exon-1 was interrupted by the pGKneo cassette (Rankin et al., 1996).

\section{Zona pellucida and fertility of $m Z P 1-3$ null females}

\section{mZP1 mutant mice}

Fully-grown oocytes from $m Z P 1-/-$ females are surrounded by a ZP that, like the ZP of oocytes from wild-type mice, consists of $\mathrm{mZP2}$ and mZP3 in roughly equimolar amounts (Rankin et al.,

\section{TABLE 2}

\section{PHENOTYPES OF mZP 1-3 NULL FEMALES}

\begin{tabular}{|c|c|c|c|c|}
\hline & \multicolumn{3}{|c|}{ Presence of a ZP } & \multirow[b]{2}{*}{ Fertility } \\
\hline & $\begin{array}{l}\text { Early-Growing } \\
\text { Oocyte }\end{array}$ & $\begin{array}{l}\text { Late-Growing } \\
\text { Oocyte }\end{array}$ & $\begin{array}{c}\text { Fully-Grown } \\
\text { Oocyte }\end{array}$ & \\
\hline Wild-Type & + & + & + & + \\
\hline $\mathrm{mZP} 1^{-/-}$ & $+^{1}$ & + & + & $+/-^{4}$ \\
\hline $\mathrm{mZP}^{-/-}$ & $t^{2}$ & - & - & -5 \\
\hline $\mathrm{mZP}^{-/-}$ & - & - & - & -5 \\
\hline $\mathrm{mZP}^{+/-}$ & $t^{3}$ & + & + & + \\
\hline
\end{tabular}

Appearance of the ZP during oocyte growth and fertility for wild-type and mZP1, 2, and 3 null female mice

${ }^{1}$ A loosely organized, abnormal ZP; ${ }^{2} \mathrm{~A}$ very thin, abnormal ZP; ${ }^{3} \mathrm{~A}$ thinner than normal ZP; ${ }^{4} \mathrm{Fewer}$ than normal offspring; ${ }^{5}$ No offspring.
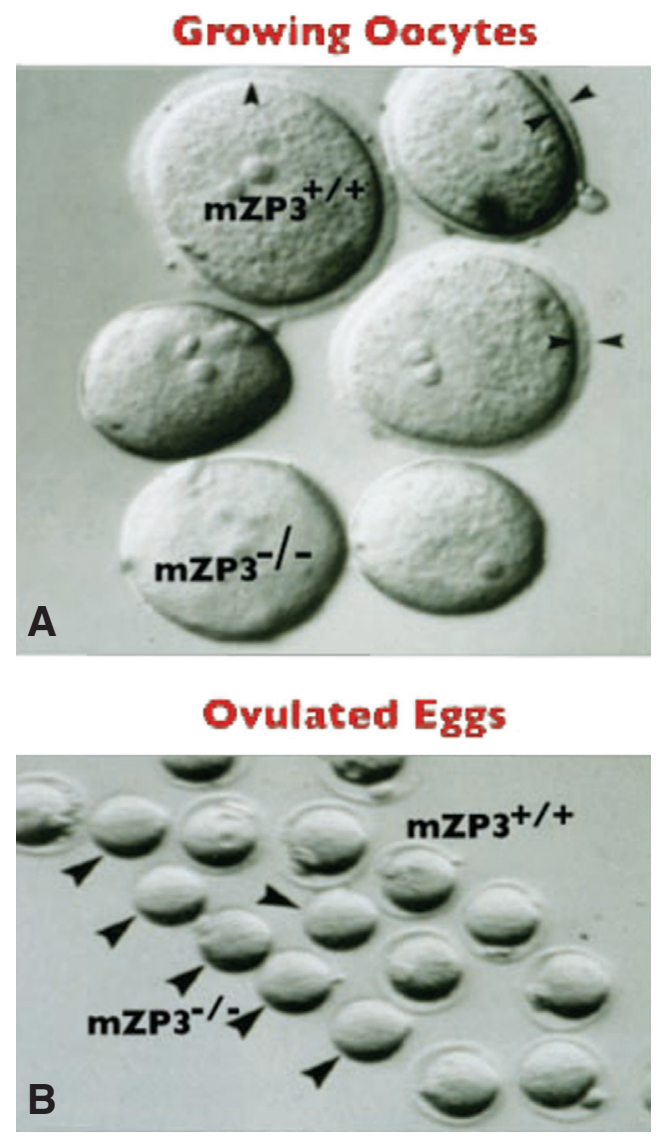

Fig. 4. Light micrographs of growing mouse oocytes and ovulated mouse eggs. (A) Growing oocytes from 17-day-old wild-type (mZP3+/+) and homozygous null (mZP3-/-) female mice. Arrowheads indicate the presence of a ZP on three growing oocytes from wild-type mice. The three growing oocytes from homozygous null mice lack a ZP. (B) Ovulated eggs from 6-week-old wild-type and homozygous null female mice. Arrowheads indicate the six ovulated eggs from homozygous null mice that lack a ZP in the presence of eleven ovulated eggs from wild-type mice that have a ZP.

1999). Therefore, a ZP can be assembled from mZP2 and mZP3 in the complete absence of mZP1. The vast majority of $m Z P 1-/-$ females are fertile, but gave birth to litters about one-half the size ( $\sim 3.6$ pups) of wild-type litters ( $~ 7.3$ pups) apparently due to early embryonic loss (Table 2).

\section{mZP2 and mZP3 mutant mice}

Fully-grown oocytes from $m Z P 2-/-$ and $m Z P 3-/-$ females completely lack a ZP, even though growing oocytes in mZP2-/females synthesize both mZP1 and mZP3 and growing oocytes in $m Z P 3-/-$ females synthesize both mZP1 and mZP2 (Liu et al., 1996; Rankin et al., 1996, 2001; Qi and Wassarman, 1999) (Fig. 4). In both cases homozygous null females are infertile, apparently as a consequence of the presence of very few, if any eggs in their oviducts as compared with wild-type females $(<5 \%)$ after gonadotrophin stimulation. Fully-grown oocytes harvested from null females undergo spontaneous meiotic maturation with emission of a first polar body, and eggs harvested from null females can be fertilized in vitro, emit a second polar body, and undergo early cleavage-stage divisions (Rankin et al., 2001; E.S. Litscher and P.M. Wassarman, unpublished observations). Consistent with 
results of earlier experiments with eggs and embryos freed of their ZP (McClaren, 1969; Bronson and McClaren, 1970), mZP2-/- and $m Z P 3-/-$ blastocysts transferred to pseudo-pregnant females fail to give rise to live births (Rankin et al., 2001). Interestingly, oocytes from $m Z P 3+/$-females are surrounded by a ZP that is approximately one-half the thickness $(\sim 2.7 \mu \mathrm{m})$ of the ZP of wild-type females $(\sim 6.2 \mu \mathrm{m})$, but the heterozygous null females are as fertile as wild-type females (Wassarman et al., 1997). These results are summarized in Table 2.

\section{The zona pellucida and ovaries of $m Z P 1-3$ null females}

\section{mZP1 mutant mice}

Ovaries from $m Z P 1$-/-females exhibit wild-type morphology, with the majority of follicles having normal architecture (Rankin et al., 1999). However, often clusters of follicle cells are found ectopically between the ZP and the oocyte's plasma membrane in the perivitelline space; an unusual situation that is significantly accentuated in pre-ovulatory follicles stimulated with gonadotrophin. Furthermore, light and electron microscopy revealed that ZP of oocytes from $m Z P 1-/-$ females were loosely organized and distorted, and were unusually thin due to stretching. Collectively, these observations suggest that, although oocytes from $m Z P 1-/-$ mice have a ZP, its structural integrity is severely compromised compared to ZP of oocytes from wild-type females.

\section{mZP2 and mZP3 mutant mice}

Ovaries from mZP2-/- and mZP3-/- females do not exhibit normal wild-type morphology (Liu et al., 1996; Rankin et al., 1996, 2001). It was noted that during the initial stages of oocyte growth in $m Z P 2-/-$ females a very thin ZP composed of mZP1 and mZP3 is present, but it is not sustained throughout oocyte growth (Rankin et al., 2001). Although oocyte growth and follicle development proceed in $m Z P 3-/-$ and $m Z P 2-/-$ females, there are fewer antral follicles present than in wild-type females and the extent of follicle cell-oocyte interaction is severely compromised (Fig. 5). The former is reflected in differences seen in the size of ovaries from wild-type and null mice. Ovaries from wild-type females are always larger than ovaries from $m Z P 3-/$ - females, with the largest difference seen in juvenile mice ( $<21$ days-of-age) that possess an unusually large number of developing follicles (Table 3). The ratio of average ovarian weights (wild-type:null) for 20-, 35-, and 70 -day-old females changes from $\sim 4$, to $\sim 1.7$, to $\sim 1.3$, respectively (Wassarman et al., 1998). This is most demonstrable in juvenile (prepubertal) females since the ovarian stroma and vasculature are incompletely developed (Ellinwood et al., 1978) and do not mask the effect of a decreased number of developing follicles on ovarian weight.

\section{Causes of $m Z P 1-3$ null phenotypes}

mZP2 and mZP3 are monomers, whereas mZP1 is a dimer composed of identical polypeptides held together by intermolecular disulfides. The ZP of oocytes from wild-type females consists of an extensive matrix of branched fibrils, however, reduction of intermolecular disulfides of $\mathrm{mZP} 1$ solubilizes the ZP and generates a population of unbranched fibrils. This, as well as other evidence strongly suggests that mZP1 serves as the cross-linker of ZP fibrils (Greve and Wassarman, 1985).
TABLE 3

\section{EFFECT OF NULL MUTATION ON WEIGHT OF OVARY}

\begin{tabular}{lcc} 
& \multicolumn{2}{c}{ Weight of Ovary $(\mathbf{m g})$} \\
\cline { 2 - 3 } Age of Females & Wild-Type & mZP3 $^{- \text {- }^{-}}$ \\
\hline 20-days & $1.0 \pm 0.17$ & $0.26 \pm 0.1$ \\
35-days & $1.7 \pm 0.17$ & $1.0 \pm 0.34$ \\
70-days & $3.6 \pm 0.43$ & $2.8 \pm 0.65$
\end{tabular}

Age of donor mice (days) versus weight of ovaries $(\mathrm{mg})$ in wild-type and $m Z P 3$ homozygous null mice

The ZP surrounding oocytes from $m Z P 1-/-$ females is quite fragile compared with the ZP of wild-type oocytes. It consists of very loosely packed fibrils composed of mZP2 and mZP3 synthesized by growing oocytes in the absence of mZP1. The poorly organized ZP permits fertilization to occur, but is vulnerable during passage of cleavage-stage embryos down the oviduct, and leads to early embryonic loss and fewer offspring (Rankin et al., 1999). Presumably, the presence of mZP2 and mZP3 supports formation of heterodimers that in turn assemble into long fibrils. However, in the absence of mZP1 the fibrils are insufficiently packed together, creating an unusually porous matrix that permits even follicle cells to enter the perivitelline space. The appearance and properties of ZP from $m Z P 1-/-$ females is entirely consistent with a lack of cross-linking of fibrils by mZP1.
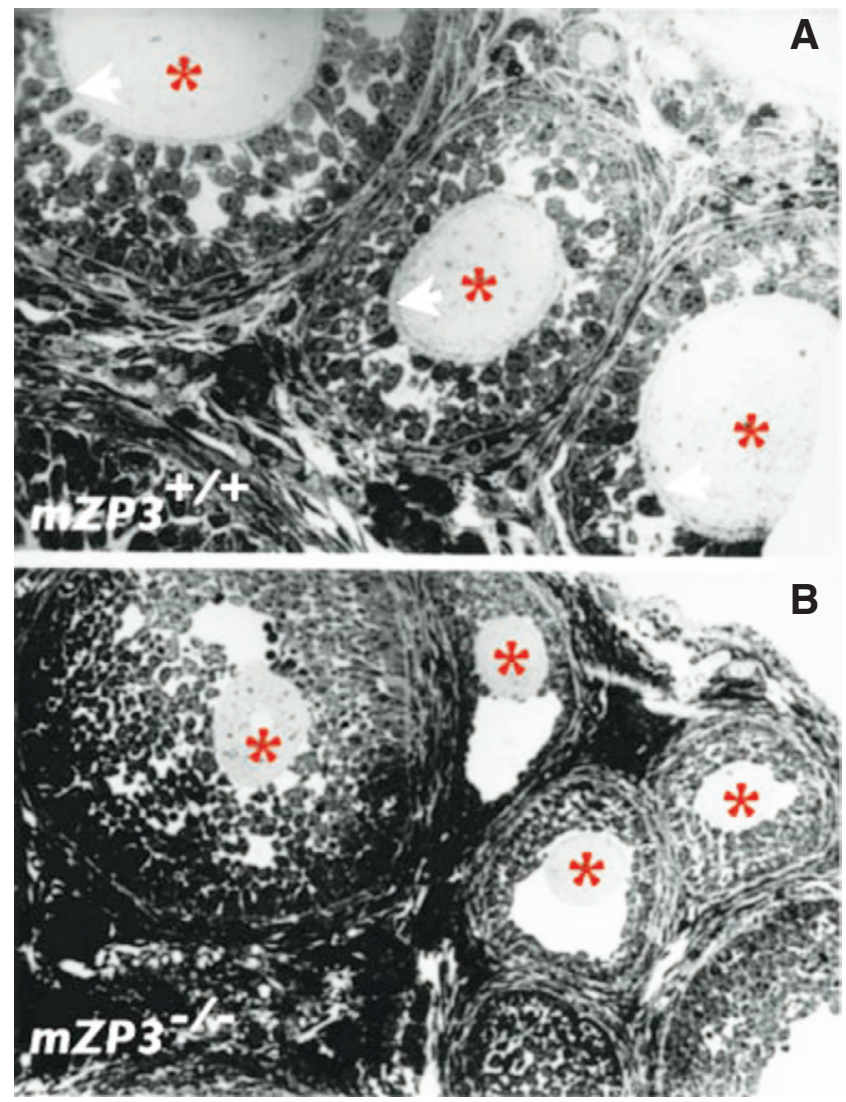

Fig. 5. Light micrographs of ovarian sections from 35-day-old female mice. (A) Section from a wild-type, mZP3+/+ mouse. (B) Section from a homozygous null, mZP3-/- mouse. Red asterisks indicate the positions of oocytes. Note that in (A) the oocytes have a $Z P$ and are in very close proximity surrounding follicle cells. Note that in $(B)$ the oocytes do not have a ZP and are only loosely associated with surrounding follicle cells. 
Growing oocytes from $m Z P 3+/$-females synthesize significantly less mZP3 than wild-type animals, a thinner than normal ZP assembles around oocytes, and the mutant females are as fertile as wild-type females (Wassarman et al., 1997). On the other hand, fully-grown oocytes and ovulated eggs from mZP2-/- and mZP3/- females completely lack a ZP and the females are infertile (Liu et al., 1996; Rankin et al., 1996, 2001). These findings strongly suggest that both nascent mZP2 and mZP3 must be present to assemble a ZP around oocytes and the absence of a ZP precludes fertilization in vivo. When either mZP2 or mZP3 is present in limiting amounts, such as in heterozygous females, a thinner than usual ZP assembles around the oocyte, but it is sufficient to support normal fertilization and development.

Failure of oocytes from $m Z P 2-/-$ and $m Z P 3-/-$ females to construct a ZP has deleterious effects on folliculogenesis, seen as a reduced number of antral follicles in ovaries and a severely reduced number of ovulated eggs in oviducts. Ovarian morphology suggests that growing and fully-grown oocytes from $m Z P 2-/-$ and $m Z P 3-/$-females are less intimately associated with follicle cells, in general, and with cumulus cells, in particular, than oocytes from wild-type females (Liu et al., 1996; Rankin et al., 1996, 2001; Wassarman et al., 1998). Notably, cells of the corona radiata in mZP2-/- and mZP3/- females are less orderly arrayed around growing oocytes than in wild-type females. Perhaps as a consequence of this disorder, the few ovulated eggs recovered from homozygous null females have a smaller number of cumulus cells around them. This is of interest since the organization and functioning of the wild-type ovary is dependent on very close interactions between the oocyte and surrounding follicle cells (Eppig, 2001; Jamnongjit and Hammes, 2005; Kidder and Vanderhyden, 2010). Communication between the oocyte and follicle cells is bidirectional; follicle cells regulate oocyte growth and the oocyte regulates follicular development.

Communication between the oocyte and surrounding follicle cells occurs, at least in part, because the developing follicle is a syncytium of cells connected by intercellular cytoplasmic channels (pore size $\sim 15 \AA$ ), called gap junctions (Harris, 2001; Sosinsky and Nicholson, 2005). Gap junctions form between the oocyte and cells of the corona radiata, the innermost cumulus cells. In addition, gap junctions form between cumulus cells, between cumulus and follicle cells not surrounding the oocyte, and between all other follicle cells. In ovaries from wild-type females microvilli emanating from the growing oocyte and long processes emanating from cells of the corona radiata traverse the $\mathrm{ZP}$ and establish gap junctions through which small molecules ( $<1,000$ relative molecular mass) can pass. Female mice that are homozygous nulls for either connexin-37 or -43 , proteins associated with ovarian follicle gap junctions, are deficient in both multilayered follicles and normal growing oocytes, and are infertile (Simon et al., 1997; Ackert et al., 2001).

Since the ZP is a highly viscous extracellular matrix, it possibly serves to stabilize gap junctions that form between the oocyte and cells of the corona radiata. Perhaps fewer gap junctions are present in the absence of a ZP and transfer of nutrients, nucleotides, metabolites, ions, etc. to the oocyte is diminished to different extents among follicles and severely compromises oocyte growth in some follicles. However, a few oocytes from mZP2-/- and mZP3-/- females achieve full growth, undergo the first meiotic division, can be fertilized in vitro, and undergo cleavage divisions. How these few oocytes overcome the difficulties associated with the absence of a ZP remains to be determined.

\section{Acknowledgements}

Many thanks to the post-doctoral fellows, graduate students, and research technicians who contributed to the research on wild-type and mutant mice carried out in our laboratory at the Roche Institute of Molecular Biology and Mount Sinai Medical School. Our research was supported in part by Hoffmann-La Roche Inc and the National Institutes of Health (NICHD).

\section{References}

ACKERT, C.L., GITTENS, J.E., O'BRIEN, M.J., EPPIG, J.J., and KIDDER, G.M. (2001). Intercellular communication via connexin43 gap junctions is required for ovarian folliculogenesis in the mouse. Dev Biol 233: 258-270.

AUSTIN, C.R. and SHORT, R.V., eds. (1982). Reproduction in Mammals: Germ Cells and Fertilization, 1, 1-177, $2^{\text {nd }}$ Ed., Cambridge Univ. Press.

BLEIL, J.D. and WASSARMAN, P.M. (1980). Structure and function of the zona pellucida: Identification and characterization of the proteins of the mouse oocyte's zona pellucida. Dev Biol 76: 185-202.

BOJA, E.S., HOODBHOY, T., FALES, H.M., and DEAN, J. (2003). Structural characterization of native mouse zona pellucida proteins using mass spectrometry. $J$ Biol Chem 278: 34189-34202.

BORK, P. and SANDER, C. (1992). A large domain common to sperm receptors (ZP2 and ZP3) and TGF-b type III receptor. FEBS Lett 300: 237-240.

BRONSON and MCLAREN (1970). Transfer to the mouse oviduct of eggs with and without the zona pellucida. J Reprod Fertil 22: 129-137.

ELLNWOOD, W.E., NETT, T.M., and NISWENDER, G.D. (1978). Ovarian vasculature: Structure and function. In The Vertebrate Ovary (R.E. Jones, ed.), 583-614, Plenum Press, NY.

EPIFANO, O., LIANG, L.-F., and DEAN, J. (1995). Mouse Zp1 encodes a zona pellucida protein homologous to egg envelope proteins in mammals and fish. $\mathrm{J}$ Biol Chem 270: 27254-27258.

EPPIG, J. (2001). Oocyte control of ovarian follicular development and function in mammals. Reproduction 122: 829-838.

FLORMAN, H.M. and DUCIBELLA, T. (2006). Fertilization in mammals. In, The Physiology of Reproduction (J.D. Neill, ed.) 1, 55-112, Elsevier, San Diego.

GREVE, J.M. and WASSARMAN, P.M. (1985). Mouse egg extracellular coat is a matrix of interconnected filaments possessing a structural repeat. JMol Biol181:253-264.

HAN, L., MONNE, M., OKUMURA, H., SCHWEND, T., CHERRY, A.L., FLOT, D., MATSUDA, T., and JOVINE, L. (2010). Insights into egg coat assembly and eggsperm interaction from the X-ray structure of full-length ZP3. Cell 143: 404-415.

HARDY, D.M., ed. (2002). Fertilization. Academic Press, San Diego. 427 pp.

HARRIS, A.L. (2001). Emerging issues of connexin channels: Biophysics fills the gaps. Quart Rev Biophys 34: 325-472.

HOODBHOY, T., AVILES, M., BAIBAKOV, B., EPIFANO, O., JIMENEZ-MOVILLA, M., GAUTHIER, L., and DEAN, J. (2006). ZP2 and ZP3 traffic independently within oocytes prior to assembly into the extracellular zona pellucida. Mol Cell Biol 26: 7991-7998.

JAMNONGJIT, M. and HAMMES, S.R. (2005). Oocyte maturation: The coming of age of a germ cell. Semin Reprod Med 23: 234-241.

JOVINE, L., QI, H., WILLIAMS, Z., LITSCHER, E.S., and WASSARMAN, P.M. (2002). The ZP domain is a conserved module for protein polymerization. Nature Cell Biol 4: 457-461.

JOVINE, L., QI, H., WILLIAMS, Z., LITSCHER, E.S., and WASSARMAN, P.M. (2004). A duplicated motif controls assembly of zona pellucida domain proteins. Proc Natl Acad Sci USA 101: 5922-5927.

JOVINE, L., DARIE, C.C., LITSCHER, E.S., and WASSARMAN, P.M. (2005). Zona pellucida domain proteins. Annu Rev Biochem 74: 83-114.

JOVINE, L., JANSSEN, W.G., LITSCHER, E.S., and WASSARMAN, P.M. (2006). The PLAC-1 homology region of the ZP domain is sufficient for protein polymerization. BMC Biochem 7: 11-19.

KEEFE, D., TRAN, P., PELLEGRINI, C., and OLDENBOURG, R. (1997). Polarized light microscopy and digital imaging processing identify a multilaminar structure of the hamster zona pellucida. Human Reprod 12: 1250-1252.

KIDDER, G.M. and VANDERHYDEN, B.C. (2010). Bidirectional communication between oocytes and follicle cells: Ensuring oocyte developmental competence. 
Can J Physiol Pharmacol 88: 399-413.

LLORCA, O., TRUJILLO, A., BLANCO, F.J., and BERNABEAU, C. (2007). Structural model of human endoglin, a transmembrane receptor responsible for hereditary hemorrhagic telangiectasia. J Mol Biol 365: 694-705.

LIU, C., LITSCHER, E.S., MORTILLO, S., SAKAI, Y., KINLOCH, R.A., STEWART, C.L., and WASSARMAN, P.M. (1996). Targeted disruption of the mZP3 gene results in production of eggs lacking a zona pellucida and infertility in female mice. Proc Natl Acad Sci USA 93: 5431-5436.

LIU, C., LITSCHER, E.S, and WASSARMAN, P.M. (1997). Zona pellucida glycoprotein mZP3 bioactivity is not dependent on the extent of glycosylation of its polypeptide or on sulfation and sialylation of its oligosaccharides. J Cell Sci 110: 745-752.

LUNSFORD, R.D., JENKINS, N.A., KOZAK, C.A., LIANG, L.F., SILAN, C.M., COPELAND, N.G., and DEAN, J. (1990). Genomic mapping of murine Zp-2 and Zp-3, two oocyte-specific loci encoding zona pellucida proteins. Genomics 6: 184-187.

McLAREN, A. (1969). Transfer of zona-free mouse eggs to uterine foster mothers. $J$ Reprod Fertil 19: 341-346.

MONNE, M., HAN, L., SCHWEND, T., BURENDAHL, S., and JOVINE, L. (2008). Crystal structure of the ZP-N domain of ZP3 reveals the core fold of animal egg coats. Nature 456: 653-657.

MONNE, M. and JOVINE, L. (2011). A structural view of egg coat architecture and function in fertilization. Biol Reprod 85: 661-669.

PLAZA, S., CHANUT-DELALANDE, H., FERNANDES, I., WASSARMAN, P.M., and PAYRE, F. (2010). From A to Z: Apical structures and zona pellucida-domain proteins. Trends Cell Biol 20: 524-532.

QI, H. and WASSARMAN, P.M. (1999). Secretion of zona pellucida glycoprotein mZP2 by growing oocytes from $m Z P 3+/+$ and $m Z P 3-/-$ mice. Dev Genetics 25: 95-102.

RANKIN, T.L., FAMILIARI, M., LEE, E., GINSBERG, A., DWYER, N., BLANCHETTEMACKIE, J., DRAGO, J., WESTPHAL, H., and DEAN, J. (1996). Mice homozygous for an insertional mutation in the ZP3 gene lack a zona pellucida and are infertile. Development 122: 2903-2910.

RANKIN, T.L., TALBOT, P., LEE, E., and DEAN, J. (1999). Abnormal zonae pellucidae in mice lacking ZP1 result in early embryonic loss. Development 126: 3847-3855.

RANKIN, T.L., O'BRIEN, M., LEE, E., WIGGLESWORTH, K., EPPIG, J., and DEAN, J. (2001). Defective zonae pellucidae in ZP2-null mice disrupt folliculogenesis, fertility, and development. Development 128: 1119-1126.

RAMIREZ-SOLIS, R., DAVIS, A.C., and BRADLEY, A. (1993). Gene targeting in embryonic stem cells. Methods Enzymol 225: 855-878.

SHIMIZU, S., TSUJI, M., and DEAN, J. (1983). In vitro biosynthesis of three sulfated glycoproteins of murine zonae pellucidae by oocytes grown in follicle culture. $J$ Biol Chem 258: 5858-5863.

SIMON, A.M., GOODENOUGH, D.A., LI, B.Y., and PAUL, D.L. (1997). Female infertility in mice lacking connexin 37. Nature 385: 525-529.

SOSINSKY, G.E. and NICHOLSON, B.J. (2005). Structural organization of gap junction channels. Biochim Biophys Acta 1711: 99-125.

TONG, Z.-B., NELSON, L.M., and DEAN, J. (1995). Inhibition of zona pellucida gene expression by antisense oligonucleotides injected into mouse oocytes. $J$ Biol Chem 270: 849-853.

WASSARMAN, P.M. (1988). Zona pellucida glycoproteins. Annu Rev Biochem 57 415-442.

WASSARMAN, P.M. (1999). Mammalian fertilization: Molecular aspects of gamete adhesion, exocytosis, and fusion. Cell 96: 175-183.

WASSARMAN, P.M. (2008). Zona pellucida glycoproteins. J Biol Chem 283: 2428524289.

WASSARMAN, P.M. and MORTILLO, S. (1991). Structure of the mouse egg extracellular coat, the zona pellucida. Intl Rev Cytol 130: 85-110.

WASSARMAN, P.M. and ALBERTINI, D. F. (1994). Cellular and molecular biology of the mammalian ovum. In, The Physiology of Reproduction (E. Knobil and J.D. Neill, eds.) 1, 79-122, Raven Press, NY.

WASSARMAN, P.M., LIU, C., and LITSCHER, E.S. (1996). Constructing the mouse egg zona pellucida: Some new pieces of an old puzzle. J Cell Sci 109: 2001-2004.

WASSARMAN, P.M., QI, H., and LITSCHER, E.S. (1997). Mutant female mice carrying a single $m Z P 3$ allele produce eggs with a thin zona pellucida, but reproduce normally. Proc $R$ Soc Lond B, Biol Sci 264: 323-328.

WASSARMAN, P.M., LIU, C., CHEN, J., QI, H., and LITSCHER, E.S. (1998). Ovarian development in mice bearing homozygous and heterozygous null mutations in zona pellucida glycoprotein gene mZP3. Histol Histopathol 13: 293-300. 


\section{Further Related Reading, published previously in the Int. J. Dev. Biol.}

Germline stem cells and sex determination in Hydra

Chiemi Nishimiya-Fujisawa and Satoru Kobayashi

Int. J. Dev. Biol. (2012) 56: 499-508

The Dr-nanos gene is essential for germ cell specification in the planarian Dugesia ryukyuensis Haruka Nakagawa, Hirotsugu Ishizu, Ayako Chinone, Kazuya Kobayashi and Midori Matsumoto Int. J. Dev. Biol. (2012) 56: 165-171

Impaired meiotic competence in putative primordial germ cells produced from mouse embryonic stem cells

Marianna Tedesco, Donatella Farini and Massimo De Felici

Int. J. Dev. Biol. (2011) 55: 215-222

A polymorphic, thrombospondin domain-containing lectin is an oocyte marker in Hydractinia: implications for germ cell specification and sex determination

Brahim Mali, R. Cathriona Millane, Günter Plickert, Marcus Frohme and Uri Frank

Int. J. Dev. Biol. (2011) 55: 103-108

Generation of germ-line chimera zebrafish using primordial germ cells isolated from cultured blastomeres and cryopreserved embryoids

Yutaka Kawakami, Rie Goto-Kazeto, Taiju Saito, Takafumi Fujimoto, Shogo Higaki, Yoshiyuki Takahashi, Katsutoshi Arai and Etsuro Yamaha

Int. J. Dev. Biol. (2010) 54: 1493-1501

5 yr ISI Impact Factor $(2011)=2.959$
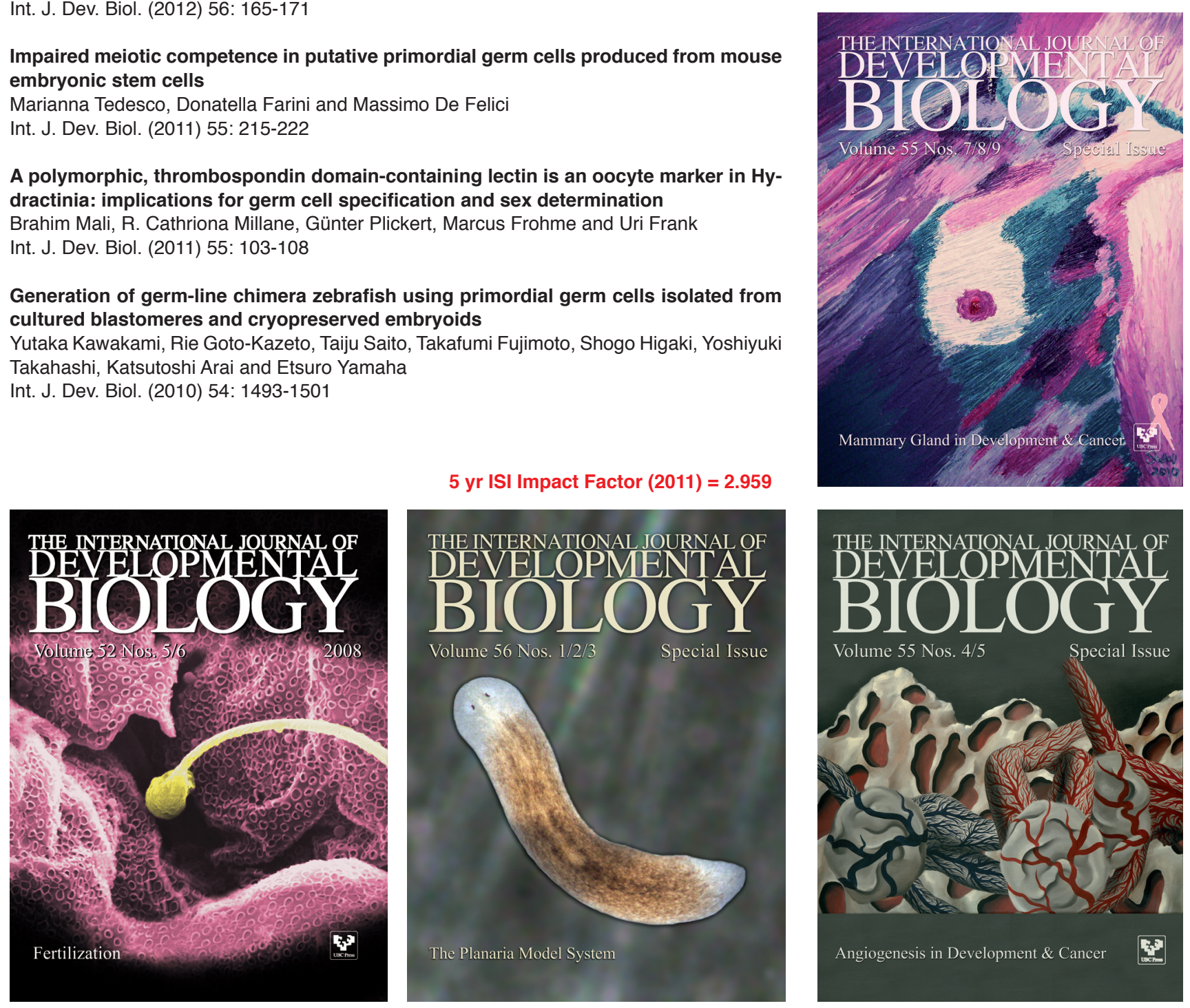